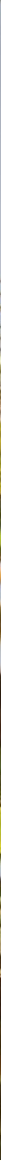

18

\title{
Moving Beyond Maize: the Evolution of Malawi's Agriculture-Nutrition Policy Dialogue
}

Noora-Lisa Aberman*

International Food Policy Research Institute (IFPRI), Accra, Ghana

* n.aberman@cgiar.org

(C) CAB International 2019. Agriculture for Improved Nutrition: Seizing the Momentum (eds S. Fan, S. Yosef and R. Pandya-Lorch) 


\section{Introduction}

In recent years, agriculture has been increasingly seen as a strong mechanism for addressing global malnutrition. More and more, agricultural actors in Malawi and beyond are under pressure to join hands with other sectors, including health, education, gender, finance and governance, and step outside of their traditional spheres of responsibility to take on nutritionsensitive activities, or those with an indirect effect on nutrition outcomes. The need for multisectoral action has been largely embraced by nutritionists globally, and for the past decade or so efforts have been focused on bringing stakeholders from agriculture, as well as from other sectors, on board. While issue salience is important - agriculture actors recognizing their sector as important for improving diets and nutrition only with thoughtful implementation of appropriate policies and programs might we see improved nutritional outcomes for the Malawian population.

Malawi is a low-income, food-deficit country with a high rate of chronic malnutrition: $37 \%$ of children aged 6-59 months are moderately or severely stunted (NSO and IFC International, 2016). Most of the population comprises subsistence farmers dependent on rain-fed agriculture, and $94 \%$ of the rural and $38 \%$ of the urban populations are engaged in agriculture, principally as smallholders with landholdings of less than 1 ha (NSO, 2012). Smallholder production is predominantly centered on maize, Malawi's main staple crop, which was grown on $80 \%$ of smallholder-cultivated land in 2011. Diets are dominated by maize, though household food consumption also includes a range of nutritious foods, but in inadequate amounts (Verduzco-Gallo et al., 2014). Each year, some subset of the population requires emergency food assistance due to unfavorable weather patterns leading to production failures. Recent seasons have been particularly dire, with approximately 2.8 million people requiring assistance in the 2015-2016 lean season just before the following harvest and approximately $6.5 \mathrm{mil}-$ lion people needing assistance in the 20162017 lean season (Government of Malawi, 2015b, 2017).

\section{Learning from the Past: Factors Driving Multisectorality}

Within the context of pervasive hunger and undernutrition, Malawi's agriculture sector is urgently concerned with ensuring sufficient calories for the population. Why and under what circumstances would it also take responsibility for broader dietary and nutrition objectives? Various country case studies have been undertaken to determine the factors that drive successful multisectoral collaboration for nutrition. Incentives for mobilization of the agriculture sector for nutrition could be financial, such as a coordinated funding stream for multisectoral nutrition activities, or organizational, such as helping collaborating institutions meet their own objectives (Garrett and Natalicchio, 2011; Mejía Acosta and Fanzo, 2012). Garrett and Natalicchio (2011) found that people-oriented leadership helped bring in partners and promote consensus. Mejía Acosta and Fanzo (2012) found that direct involvement of the executive branch at the presidential or prime ministerial level was critical. In addition to these factors, the framing of the issue should be relevant to the national agenda and speak to the specific objectives and priorities of the collaborating institutions.

This chapter examines the headway that has been made in Malawi in bringing the agriculture sector on board as a partner in addressing malnutrition multisectorally, and the factors that are driving progress. It also examines the challenges and gaps that remain both in framing the issue and moving from rhetoric to action.

\section{Agriculture Policy in a Context of Chronic Hunger}

In Malawi, as in many countries, agriculturesector policies are chiefly focused on the production of staple food crops (Pingali, 2015); more specifically in Malawi, the production of maize. In the context of dependence on rain-fed agriculture and chronic hunger, food security is among the top concerns, and it tends to be understood narrowly as an issue of ensuring sufficient maize production. For instance, the 
primary indicator for the country's food-security status is maize production estimates. Due to its perceived importance to food security, maize is also at the center of agriculture policy and even influences electoral politics (Chinsinga, 2011; Mpesi and Muriaas, 2012). 'Maize is life', 'maize is food', and 'maize is politics' are common phrases among policy stakeholders and farmers alike (Smale, 1995; Chinsinga, 2011; Aberman et al., 2018). In recent years, there have been two instances during which the president of Malawi acted as the de facto Minister of Agriculture, Irrigation and Water Development (MoAIWD, previously the Ministry of Agriculture and Food Security), first by President Bingu wa Mutharika in 2008 and subsequently by his brother President Peter Mutharika in 2017, further highlighting the national importance and politicization of the sector (Aberman et al., 2012).

That agriculture policies and programs are heavily centered on maize is further exemplified by the role of government subsidies for inputs, known as the Farm Input Subsidy Program (FISP) in its current iteration. Promising a return to subsidized fertilizers in his 2004 campaign for election, President Bingu wa Mutharika implemented the precursor to the FISP to promote long-term maize self-sufficiency at the farm level (Mpesi and Muriaas, 2012). The aim of this precursor program was to enable people to grow and eat their own 'food', i.e. maize. The program was considered a major success by most, with Bingu being praised at home and globally for his role in increasing maize production to surplus levels, providing him significant political capital (FANRPAN, 2008; Dorward and Chirwa, 2011). However, many have argued more recently that the program's effects were not as strong or lasting as was hoped. Ex-post analysis suggests that estimates of production increases are likely inflated, targeting is inefficient, and benefits to households are largely limited to the current production season, making FISP an expensive program (Ricker-Gilbert and Jayne, 2011; Holden and Lunduka, 2013; Lunduka et al., 2013; Pauw and Thurlow, 2014).

Despite its shortcomings, FISP comprises a major share of the agricultural budget. For instance, in 2008-2009, it accounted for 74\% of agricultural spending (Ragasa et al., 2016).
In 2012-2013 and 2013-2014, it accounted for $58 \%$ and $44 \%$ of agricultural spending, respectively, fluctuating with global fertilizer prices and other factors. Added together with other agriculture programs that focus on maize, such as price supports for maize, agricultural spending is also aligned with the maize-centric approach to agricultural production and the perception of what constitutes food security in Malawi, in effect crowding out more comprehensive approaches to food and nutrition security.

Despite strong investment in agriculture, the country still faces periodic maize deficits and an annual need for food aid for the poorest Malawians. Thus, while the emphasis on staple food production is understandable in a setting where hunger is a pressing challenge, up to now this limited approach has not even yielded sustainable results for maize availability. While people's strong preference for maize in their diets is often cited by policy-makers as the reason for maize-centric polices, the political nature of maize in the country provides additional insights into why it is challenging to shift investment away from maize, even if there is will to do so. With poverty and malnutrition still at relatively high levels, despite some improvements, a more comprehensive approach to food and nutrition security is essential.

\section{Rising Importance of Multisectorality and the Role of Agriculture}

There has been a rising tide of attention to food security and nutrition more broadly, by development partners, researchers, and program implementers both in Malawi and globally, including an acknowledgement of the role that the agriculture sector plays in nutrition (World Bank, 2013). Furthermore, there is now better understanding of the virtuous effects of better nutrition on individuals' social and economic potential, and the synergies between healthy food systems and a strong agriculture sector (Government of Malawi, 2015a; Kanter et al., 2015).

Central to multisectoral nutrition, the Scaling Up Nutrition (SUN) movement is a globally recognized effort to address malnutrition. Malawi joined the SUN movement as an 'Early Riser' in 
early 2011 (SUN, 2018). SUN functions largely as a convener of stakeholders, supporting information sharing and coherence in funding and action.

Building on the momentum of SUN and other initiatives, the International Food Policy Research Institute (IFPRI) convened a highprofile event in Malawi on 'Unleashing Agriculture's Potential for Improved Nutrition and Health' in September 2011. This conference partnered with the MoAIWD to discuss agricultural strategies that can promote improvements in nutrition and health.

Currently, all of the major donors and implementers of programs focused on nutrition or food security in Malawi tend to consider the issues of agriculture, food security, and nutrition as interrelated, and their programming reflects this viewpoint. For instance, the Government of Flanders and the Food and Agriculture Organization (FAO) of the United Nations (UN) supported 'Improving Food Security and Nutrition Policies and Programme Outreach' from 2011 to 2015, promoting education related to healthy diets for infants and young children through existing government mechanisms within the Ministry of Agriculture and Food Security/MoAIWD and the Ministry of Health (FAO, 2015). Flagship programs of the US Agency for International Development (USAID) have also focused on integrating nutrition into agriculture. In 20122015, USAID's 'Feed the Future Integrating Nutrition in Value Chains' program promoted the production and marketing of nutritious crops by smallholders (Mucha, 2015). Subsequently, USAID's 'Strengthening Agricultural and Nutrition Extension' program, which began in 2015, seeks to strengthen integrated agriculture and nutrition extension services (Cadrin and McNamara, 2016). In 2016, the Japan International Cooperation Agency launched 'Initiative for Food and Nutrition Security in Africa' to support African governments, including Malawi, to accelerate the implementation of their food and nutrition security policies on the ground and decrease malnutrition through nutrition-specific and nutrition-sensitive actions (JICA, 2016). These are just a few examples of integrated programming focusing explicitly on strengthening the agriculture sector's response to malnutrition.

Researchers have also focused on the potential synergies and missed opportunities between agriculture and nutrition in Malawi. As discussed in Aberman et al. (2018), there are challenges to undertaking this type of analysis with the available nationally representative data because of the 'data disconnect', wherein highquality agricultural data are not available in the same datasets as data on individual diets, which is a key factor linking agriculture to nutrition (Gillespie et al., 2012). Nevertheless, researchers have been able to examine household consumption as a precursor to diets of individuals, or use survey data collected from a smaller subset of the population to extrapolate to the broader population. Other analyses have focused on understanding the maize-first preferences of Malawians, and how the country's food and agriculture systems promote maize to the detriment of balanced and diverse diets. Aberman and Roopnaraine (2018) found that Malawians understand the value of diverse diets but cannot afford them, since they often have to sell nutritious crops to meet urgent cash needs. Gelli et al. (2017) found that food aid (provided to the country's food-insecure households each lean season by the Malawi Vulnerability Assessment Committee), made up primarily of maize and legumes, frees up resources so that households can consume other nutritious foods.

Other researchers have examined crop diversification and the quality of diets in Malawi. For instance, Snapp and Fisher (2014) found that FISP does not decrease crop diversification or household dietary diversity, but can actually support both by 'filling the maize basket' more efficiently, freeing up land to devote to other crops. Jones et al. (2014) found that crop diversification on smallholder farms increases household dietary diversity, though more so for wealthier households. Furthermore, providing nutrition education along with agricultural interventions to support the production of nutritious foods is even more effective for improving diets than agricultural interventions alone (Bezner Kerr et al., 2011).

Analysis of dietary patterns by Pauw et al. (2018) showed that maize prices decreased and household food consumption increased between 2004 and 2011. However, during the same time period, the prices of leafy green vegetables increased and household food consumption decreased, suggesting that supports to maize production may be changing relative prices and, hence, dietary patterns. 


\section{Changing Tides or Shallow Pools?}

Calls for the agriculture sector to play a greater role in coordinated efforts to improve nutrition, have influenced the policy narrative in Malawi. During the past decade or so, nutrition has become a salient issue among agriculture-sector actors and, importantly, within MoAIWD. The synergies between agriculture and nutrition are now widely acknowledged. Formal addresses by government representatives now commonly refer to nutrition-relevant concepts. Recently developed policy documents contain nutritionsensitive language, such as the National Agriculture Policy approved in 2016 wherein one of the eight policy priorities highlighted is 'Food and Nutrition Security' (Government of Malawi, 2016). Another relevant example is the Agriculture Sector Food and Nutrition Strategy that was being formulated by MoAIWD at the time of writing. The strategy describes agriculture as the basis of food and nutrition security in that it has the primary role of feeding people well.

While the policy narrative and the content of policy documents reflect an appreciation for the responsibility of agriculture to improve nutrition, the extent to which investments in or implementation of government programs have incorporated multisectoral objectives is much more limited. This gap can be explained by weaknesses in incentives, leadership, and issue framing, all critical for successful multisectoral collaboration as previously discussed.

Conceptually, nutrition tends to still be primarily understood through a health-sector lens and secondarily as a multisectoral issue. In 2004, the Department of Nutrition, HIV and AIDS was established in the Office of the President and Cabinet to coordinate multisectoral actions, policies, and programs. It was led by Principal Secretary Mary Shawa, considered a strong champion for nutrition in Malawi. However, donor-supported public-sector reform moved the Department to the Ministry of Health in 2010 and cabinet reshuffling took Dr Shawa out of the Department entirely in 2012 (Babu et al., 2016). The Department's move to the Ministry of Health is largely viewed as detrimental to multisectorality, reinforcing the framing of nutrition as a health-sector issue. Project implementers working within the nexus of agriculture and nutrition must typically choose a ministerial host for their activities, embedding their projects within either agriculture or health. Another disadvantage of this move is that the Department is no longer led by a principal secretary, diminishing its power to champion multisectoral action on nutrition. While SUN spearheads efforts to promote improvements in nutrition through multisectoral action, it is led by the Department in the Ministry of Health. Agriculture does not play a leading role therein, nor is it held to account for nutrition outcomes.

Agriculture-sector ownership and responsibility for improved diets and nutrition (or the mediating factors leading to nutrition outcomes) remains minimal in other ways. For instance, at the national level, Ministry leadership often delegates the Department of Agriculture Extension Services to engage in nutrition-related activities. Sidelining nutrition issues into one section of the Ministry reflects a narrow interpretation of agriculture's role in nutrition-sensitive action.

The understanding of what agriculture can or should be doing to support nutrition is currently restricted to a few specific concepts that fit easily into the existing policy narrative, such as diversification. Crop diversification is a common agriculture objective and is interpreted as being akin to diet diversification, a common nutrition objective. However, there are often misunderstandings about the subtle distinctions between the term as it is used in agriculture versus in nutrition. In addition, the causal pathways from agriculture policies and actions to impacts on nutrition are not often thought out or understood among agriculture-sector actors.

Harris (2017) describes the tendency for multisectoral groups to bring different interests on board through the use of buzzwords that are strategically ambiguous. This practice allows multiple actors to appear to be working in different ways towards the same collective objective, but underlying conflicts of interests and objectives may be masked. For instance, nutritionists promote diversification across foods or food groups based on their nutritional content, with the aim of increasing micronutrient intake. Conversely, agriculturalists may view diversification to be adding any new crops to a farm or production system, whether staple crops or cash crops, in order to diversify or enhance marketing opportunities and income. Thus, the implications 
of the two approaches could be very different, and the latter may not have any effect on diets if the causal pathways are not anticipated accurately. When nutrition stakeholders discuss the need to diversify diets through a more diverse agricultural system, agriculture stakeholders can easily agree to support crop diversification. But without explicit consideration of the causal pathways - if, for instance, crops are not nutritious and socially acceptable food crops - diversification may not have any effect on diet quality.

The narrative is slowly changing. Recently, in the wake of massive crop failures and humanitarian responses in 2016 and 2017, development actors developed a narrative described as 'breaking the cycle of hunger' in Malawi, such as was discussed in the IFPRI-led Compact2025 Forum that examined the barriers to ending hunger and undernutrition by 2025 (IFPRI, 2017). While this framing still incorporates the traditional agriculture-sector objective of feeding the people, it also brings in issues of food-system resilience, natural-resource management, and other cross-sectoral issues. Because it emphasizes reflection on what has not worked in the current set of policies, it has included a strong critique of maize-centric agriculture policies. This shift may represent an opening for a new and more effective set of approaches to nutrition-sensitive programming.

\section{Conclusion}

During the past decade, various stakeholders in Malawi - including donors, program implementers, and researchers - have successfully increased the salience of multisectoral nutrition, prompting the agriculture sector to recognize its important role in addressing undernutrition. This shift is evident in the current narrative used by agriculture actors, including within formal policy statements and documents. However, effective implementation of nutrition-sensitive programming by the MoAIWD has lagged behind the rhetoric. Exploring the challenges related to leadership, issue framing, incentives and political will could shed light on why and provide lessons for other countries engaged in a similar process.

Malawi lacks high-level nutrition champions who can engage in political debates on the country's priorities. Currently, responsibility for advancing nutrition within the health and agriculture ministries lies largely in the hands of director- and deputy director-level staff who have limited ability to influence national priorities and limited power to advocate for nutrition. Thus, while nutrition enjoys issue salience and improved implementation by donors, international organizations, and civil society, there is little political progress on shifting public investment away from maize support to make room for a more comprehensive approach to food security and effective nutrition-sensitive agriculture programming.

Looking ahead, there are many promising approaches that could be more strongly emphasized in agriculture programming, and could be considered low-hanging fruit for the agriculture sector. These include:

- A stronger emphasis on production support including inputs and extension services explicitly for nutrient-dense foods, especially traditional and wild foods.

- Improving market infrastructure such as storage and transport facilities for highly perishable products and for products susceptible to aflatoxin contamination.

- Decreasing seasonality of some nutritious foods by, for instance, introducing varieties of tree fruits with varied growing seasons and supporting irrigation for home vegetable gardens.

- Providing better management of small livestock to facilitate the use of manure for soil fertility and decrease negative effects of children's exposure to zoonotic diseases.

The Department of Nutrition, HIV and AIDS, the convener of SUN, serves as an active coordination body for promoting multisectoral nutrition. However, SUN is led by nutritionists and embedded in the health sector, with the MoAIWD lacking ownership and incentives for engaging in it. A more inclusive approach to leadership, such as placing the Department outside the line ministries, would facilitate cross-sectoral ownership. Furthermore, creating specific and concrete roles and responsibilities for different sector collaborators is important.

In addition, it is useful to ask how the MoAIWD benefits from active participation in multisectoral coordination meetings or even 
ultimately from improvements in diets and undernutrition, when its success is fundamentally judged by maize yields. Thus, determining how to incentivize the agriculture ministry's ownership of dietary and nutrition outcomes is critical. As mentioned previously, a funding stream managed outside the ministerial silos to support coordinated action may be an optimal solution (Mejía Acosta and Fanzo, 2012). Expanding the food security metric beyond maize yields would provide opportunities for non-financial incentives for MoAIWD.

The current narrative frames concepts such as diversification as central to nutrition-sensitive agriculture, providing an easy call to action for the sector. However, it also results in strategic ambiguity, masking the underlying conflict - or at least lack of cohesion-between the approaches and objectives of nutrition actors and agriculture actors. A reframing of the issue, such as the recent focus on 'breaking the cycle of hunger', could more effectively integrate nutrition and agriculture-sector objectives.
Ultimately, moving away from maize-focused investments and activities is politically challenging, especially given the dearth of highlevel leadership and the political nature of maize security in the country. To some extent, debates about the technical challenges related to what the agriculture sector can and should be doing to better support nutrition may mask the underlying politics. Nevertheless, the salience of nutrition as a multisectoral issue and as a policy priority has increased among stakeholders and decision-makers in Malawi, and specifically within the MoAIWD. This success can be built upon, perhaps starting with a reframing of the issue to increase high-level support - thus paving the way for other actions - for a new approach to food and nutrition security in the country.

\section{Acknowledgements}

Thanks to Todd Benson, Jody Harris and Stacia Nordin for their comments and insights.

\section{References}

Aberman, N.-L. and Roopnaraine, T. (2018) Understanding household preferences on the production, consumption, and sale of nutritious crops. In: Aberman, N., Meerman, J. and Benson, T. (eds) Agriculture, Food Security, and Nutrition in Malawi: Leveraging the Links. IFPRI Food Policy Report. International Food Policy Research Institute, Washington, DC, pp. 30-40.

Aberman, N.-L., Johnson, M., Droppelmann, K., Schiffer, E., Birner, R. and Gaff, P. (2012) Mapping the Contemporary Fertilizer Policy Landscape in Malawi: a Guide for Policy Researchers. IFPRI Discussion Paper No. 1204. International Food Policy Research Institute, Washington, DC.

Aberman, N., Meerman, J. and Benson, T. (eds) (2018) Agriculture, Food Security, and Nutrition in Malawi: Leveraging the Links. IFPRI Food Policy Report. International Food Policy Research Institute, Washington, DC.

Babu, S.C., Haggblade, S., Mkandawire, E., Nankhuni, F. and Hendriks, S.L. (2016) Micronutrient policy process in Malawi (November). IFPRI Discussion Paper 01568. International Food Policy Research Institute, Washington, DC. Available from: http://ebrary.ifpri.org/cdm/ref/collection/p15738coll2/ id/130844 (accessed 19 December 2018).

Bezner Kerr, R., Berti, P.R. and Shumba, L. (2011) Effects of a participatory agriculture and nutrition education project on child growth in northern Malawi. Public Health Nutrition 14(8), 1466-1472. doi: 10.1017/ S1368980010002545.

Cadrin, M. and McNamara, P.E. (2016) Strengthening Agricultural and Nutrition Extension. Annual Report 2015-2016. University of Illinois, Urbana, Illinois.

Chinsinga, B. (2011) Seeds and subsidies: the political economy of input programmes in Malawi. IDS Bulletin, 42(4), 59-68. doi: 10.1111/j.1759-5436.2011.00236.x.

Dorward, A.R. and Chirwa, E. (2011) The Malawi agricultural input subsidy programme: 2005/06 to 2008/09. International Journal of Agricultural Sustainability 9(1), 232-247. doi: 10.3763/ijas.2010.0567.

FANRPAN (2008) Malawi's President wins inaugural FANRPAN Food Security Policy Leadership Award. Available at: https://www.fanrpan.org/archive/documents/d00578/ (accessed 20 February 2018).

FAO (2015) IFSN and IMCF Dissemination Meeting. Lilongwe, Malawi. Food and Agriculture Organization of the United Nations, Rome. 
Garrett, J. and Natalicchio, M. (eds) (2011) Working Multisectorally in Nutrition: Principles, Practices, and Case Studies. International Food Policy Research Institute (IFPRI), Washington, DC.

Gelli, A., Aberman, N.-L., Margolies, A., Santacroce, M., Baulch, B. and Chirwa, E. (2017) Lean-season food transfers affect children's diets and household food security: evidence from a quasi-experiment in Malawi. The Journal of Nutrition 147(5), 869-878. doi: 10.3945/jn.116.246652.

Gillespie, S., Harris, J. and Kadiyala, S. (2012) The Agriculture-Nutrition Disconnect in India What Do We Know? International Food Policy Research Institute (IFPRI), Washington, DC.

Government of Malawi (2015a) The Cost of Hunger in Malawi: The Social and Economic Impact of Child Undernutrition in Malawi. Lilongwe, Malawi.

Government of Malawi (2015b) The Malawi Vulnerability Assessment Committee ( MVAC ) National Food Security Forecast, April 2015 to March 2016. Lilongwe, Malawi.

Government of Malawi (2016) National Agriculture Policy. Lilongwe, Malawi. Available at: extwprlegs1.fao. org/docs/pdf/mlw141073.pdf (accessed 19 December 2018).

Government of Malawi (2017) The Malawi Vulnerability Assessment Committee (MVAC) National Food and Nutrition Security Forecast, April 2016 to March 2017. Lilongwe, Malawi. Available at: http://documents. wfp.org/stellent/groups/public/documents/ena/wfp285528.pdf?_ga=1.222062168.1388291131.14906 54157 (accessed 19 December 2018).

Harris, J. (2017) National Manifestation of an International Idea: Multi-Sectoral Approaches to Stunting Reduction and the Transfer of Nutrition Policy to Zambia. University of London, London.

Holden, S.T. and Lunduka, R.W. (2013) Who benefits from Malawi's Targeted Farm Input Subsidy Program? Forum for Development Studies 40(1), 1-25. doi: 10.1080/08039410.2012.688858.

IFPRI (2017) Moving from relief to resilience: achieving sustainable food security for Malawi. In: Compact2025 Malawi Forum (pp. 1-3). International Food Policy Research Institute (IFPRI), Lilongwe, Malawi. Available at: https://www.compact2025.org/files/2017/11/Compact2025-Forum-Malawi-Synopsis2.pdf (accessed 19 December 2018).

JICA (2016) Initiative for Food and Nutrition Security in Africa (IFNA) Declaration. Japan International Cooperation Agency, Nairobi, Kenya.

Jones, A.D., Shrinivas, A. and Bezner-Kerr, R. (2014) Farm production diversity is associated with greater household dietary diversity in Malawi: Findings from nationally representative data. Food Policy 46, 1-12. doi: 10.1016/j.foodpol.2014.02.001.

Kanter, R., Walls, H.L., Tak, M., Roberts, F. and Waage, J. (2015) A conceptual framework for understanding the impacts of agriculture and food system policies on nutrition and health. Food Security 7(4), 767-777. doi: 10.1007/s12571-015-0473-6.

Lunduka, R., Ricker-Gilbert, J. and Fisher, M. (2013) What are the farm-level impacts of Malawi's farm input subsidy program? A critical review. Agricultural Economics 44(6), 563-579. doi: 10.1111/agec.12074.

Mejía Acosta, A. and Fanzo, J. (2012) Fighting Maternal and Child Malnutrition: Analysing the Political and Institutional Determinants of Delivering a National Multisectoral Response in Six Countries. A synthesis paper. Institute of Development Studies (IDS), Brighton.

Mpesi, A.M. and Muriaas, R.L. (2012) Food security as a political issue: the 2009 elections in Malawi. Journal of Contemporary African Studies 30(3), 377-393. doi: 10.1080/02589001.2012.689624.

Mucha, N. (2015) The Feed the Future Integrating Nutrition in Value Chains Project Performance Evaluation Final Report. US Agency for International Development (USAID), Washington, DC.

NSO (2012) Third Integrated Household Survey (IHS3) 2010/11. National Statistical Office, Zomba, Malawi.

NSO and IFC International (2016) Malawi Demographic and Health Survey 2015-16: Key Indicators Report. National Statistical Office, Zomba, Malawi, and IFC International, Rockville, Maryland.

Pauw, K. and Thurlow, J. (2014) Malawi's Farm Input Subsidy Program: Where Do We Go From Here? Malawi Strategy Support Program Policy Note 18. International Food Policy Research Institute (IFPRI), Washington, DC.

Pauw, K., Verduzco-Gallo, I. and Ecker, O. (2018) Poverty, Food Prices and Dietary Choices in Malawi. In: Aberman, N., Meerman, J. and Benson, T. (eds) Agriculture, Food Security, and Nutrition in Malawi: Leveraging the Links. IFPRI Food Policy Report. International Food Policy Research Institute, Washington, DC, pp. 41-52.

Pingali, P. (2015) Agricultural policy and nutrition outcomes - getting beyond the preoccupation with staple grains. Food Security 7(3), 583-591. doi: 10.1007/s12571-015-0461-x. 
Ragasa, C., Mazunda, J. and Kadzamira, M. (2016) The impact of agricultural extension services in the context of a heavily subsidized input system: the case of Malawi. World Development 105, 1-26. doi: 10.1016/J.WORLDDEV.2017.12.004.

Ricker-Gilbert, J. and Jayne, T.S. (2011) What are the Enduring Effects of Fertilizer Subsidy Programs on Recipient Farm Households? Evidence from Malawi. Staff Paper No. 2011-9. Dept of Applied Economics, University of Minnesota, East Lansing, Minnesota.

Smale, M. (1995) 'Maize is life': Malawi's delayed Green Revolution. World Development 23(5), 819-831. doi: 10.1016/0305-750X(95)00013-3.

Snapp, S.S. and Fisher, M. (2014) 'Filling the maize basket' supports crop diversity and quality of household diet in Malawi. Food Security 7, 83-96. doi: 10.1007/s12571-014-0410-0.

SUN (2018) Scaling Up Nutrition: Malawi. Available at: http://scalingupnutrition.org/sun-countries/malawi/ (accessed 8 March 2018).

Verduzco-Gallo, I., Ecker, O. and Pauw, K. (2014) Changes in Food and Nutrition Security in Malawi Analysis of Recent Survey Evidence. International Food Policy Research Institute (IFPRI), Washington, DC, and Lilongwe, Malawi.

World Bank (2013) Improving Nutrition through Multisectoral Approaches. World Bank, Washington, DC. 